\title{
LA ASISTENCIA JURÍDICA GRATUITA A LAS MUJERES VÍCTIMAS DE VIOLENCIA DE GÉNERO
}

\author{
Raquel LÓPEZ MERCHÁN \\ LICENCIADA EN DERECHO \\ UNIVERSIDAD DE SALAMANCA
}

SUMARIO: I. Introducción sobre la violencia de género. II. Derechos otorgados a las mujeres víctimas de violencia de género. II.r. Derechos recogidos en la Ley Orgánica I/2004, de 28 de diciembre, de Medidas de Protección Integral contra la Violencia de Género y Ley I3/20IO, de 9 de diciembre, contra la Violencia de Género en Castilla y León. II.2. Derechos de las mujeres inmigrantes. III. Vulnerabilidad de las mujeres inmigrantes. IV. El derecho a la asistencia jurídica gratuita. IV.I. Definición de este derecho según la Ley Orgánica I/I996, de Io de enero, de Asistencia Jurídica Gratuita. IV.2. Requisitos para su otorgamiento. IV.3. Intervención preceptiva de abogado/a y procurador/a. IV.4. Solicitud del derecho a la asistencia jurídica gratuita por las mujeres inmigrantes en situación administrativa irregular. V. Bibliografía, legislación y otros recursos.

RESUMEN: El presente trabajo pretende mostrar las dificultades con las que se encuentran las mujeres víctimas de violencia de género, en concreto, las mujeres inmigrantes, cuando acuden a solicitar un/a abogado/a de oficio para que les asista en el proceso penal y civil.

Palabras ClaVE: asistencia jurídica gratuita, mujeres inmigrantes, violencia de género.

\section{THE LEGAL AID FOR IMMIGRANT WOMEN GENDER VIOLENCE}

ABSTRACT: This paper aims to show the difficulties that women are victims of gender violence, in particular immigrant women, when they come to apply for a lawyer by the court to assist them in criminal and civil liability.

KEYWORDS: free legal assistance, immigrant women, domestic violence.

\section{Introducción}

En la Ley Orgánica I/2004, de 28 de diciembre, de Medidas de Protección Integral contra la Violencia de Género (en adelante LOVG) ${ }^{\mathrm{I}}$, se habla en el art. I.3 sobre el contenido de la violencia de género, estableciendo que comprende «todo acto de violencia física $y$

\footnotetext{
I Boletín Oficial del Estado (BOE) n ${ }^{\circ} 313$, de 29 de diciembre de 2004.
} 
psicológica, incluidas las agresiones a la libertad sexual, las amenazas, las coacciones o la privación arbitraria de libertad».

Previamente, en el apartado I del mismo artículo se alude a la persona que debe infligir esta violencia: «...la violencia que (...) se ejerce sobre éstas (las mujeres) por parte de quienes sean o hayan sido sus cónyuges o de quienes estén o hayan estado ligados a ellas por relaciones similares de afectividad, aún sin convivencia».

El art.I.3 LOVG se tiene que poner en relación con el art. 87 ter de la Ley Orgánica $6 / 85$, de I de julio, del Poder Judicial que ha sido modificada por el art. 44 de la LOVG. Según se establece en este precepto, los «delitos relacionados con la violencia de género» son aquellos delitos que se recogen en los títulos del Código Penal que se refieren $\mathrm{a}^{2}$ :

- Homicidio,

- Aborto,

- Lesiones,

- Lesiones al feto,

- Delitos contra la libertad,

- Delitos contra la integridad moral,

- Delitos contra la libertad e indemnidad sexuales,

- Cualquier otro delito cometido con violencia o intimidación,

- Cualquier otro delito contra los derechos y deberes familiares: el quebrantamiento de los deberes de custodia, la inducción de menores al abandono de domicilio, la sustracción de menores y el abandono de familia, menores o incapaces.

En diciembre de 2010 vio la luz la Ley I3/20Io, de 9 de diciembre, contra la violencia de género de Castilla y León ${ }^{3}$. En su exposición de motivos se da una definición de lo que es violencia de género para el legislador castellano leonés: «cualquier acto de violencia hacia las mujeres que se ejerce contra ellas por el hecho de serlo, y que tenga o pueda tener como resultado un daño o sufrimiento físico, sexual o psicológico, incluso las amenazas de tales actos, la coacción o la privación arbitraria de la libertad tanto si se produce en la vida pública como privada, comprendiendo las distintas formas de violencia física, psicológica, sexual $y$ económica, que tienen lugar en los ámbitos de la pareja, familiar, laboral $y$ socio-comunitario».

En el art. 2 de esta ley se da una definición más escueta que en la exposición de motivos: «...cualquier acto de violencia hacia las mujeres, que se ejerce contra ellas por el hecho de serlo, y que tenga o pueda tener como resultado un daño o sufrimiento físico, sexual o psicológico, incluyendo las amenazas de tales actos, la coacción o la privación arbitraria de la libertad, tanto si se produce en la vida pública como privada».

En esta definición se engloban a todas aquellas manifestaciones de violencia hacia la mujer, las cuales son expresión de la desigualdad y de las relaciones de poder de los hombres hacia ellas. Las formas que pueden adquirir estas manifestaciones son:

${ }^{2}$ VV.AA. «Guía Práctica de la Ley Orgánica I/2004, de 28 de diciembre, de Medidas de Protección Integral contra la Violencia de Género». Consejo General del Poder Judicial, 2005. Esta guía ha sido elaborada por el Grupo de Expertos del Observatorio contra la Violencia Doméstica y de Género, designados por el Consejo General del Poder Judicial, con la finalidad de ayudar a los profesionales del Derecho en la interpretación de las normas sobre violencia de género del sistema judicial.

${ }^{3}$ Boletín Oficial de Castilla y León (BOCYL) n 243, de 20 de diciembre de 2010. 
- Violencia física.

- Violencia psicológica.

- Violencia sexual.

- Violencia económica.

- Tráfico y trata de mujeres y niñas con fines de explotación.

- Violencia originada por la aplicación de las tradiciones culturales que atenten o vulneren los derechos humanos.

- Acoso sexual.

- Acoso laboral por razón de género.

- Cualquier otra forma de violencia que lesione o sea susceptible de lesionar la dignidad, la integridad o la libertad de las mujeres basada en la pertenencia al sexo femenino.

Tenemos que tener claro que todas estas formas de expresar la violencia se pueden manifestar en distintos ámbitos:

- Dentro de la pareja, ex pareja o relación de afectividad análoga.

- Dentro de la familia.

- En el ámbito laboral.

- En el entorno social o comunitario.

\section{Derechos otorgados a las mujeres víctimas de violencia de género}

Las mujeres víctimas de violencia de género tienen reconocidos expresamente unos derechos que les son propios y que sirven para conciliar sus obligaciones y la protección que desde el Estado, las Comunidades Autónomas y/o los Ayuntamientos se les pueda otorgar.

II.I. Derechos recogidos en la Ley Orgánica I/2004, de 28 de diciembre, de Medidas de Protección Integral contra la Violencia de Género y en la Ley I3/20IO, de 9 de diciembre, contra la Violencia de Género en Castilla y León

Los derechos que son reconocidos a la mujer víctima de violencia de género aparecen regulados en el Título II de la LOVG, el cual está distribuido en cuatro capítulos que contienen los siguientes derechos:

- Capítulo I: Derecho a la información, a la asistencia social integral y a la asistencia jurídica gratuita.

- Capítulo II: Derechos laborales y prestaciones a la Seguridad Social.

- Capítulo III: Derechos de las funcionarias públicas.

- Capítulo IV: Derechos económicos.

La ley de Castilla y León habla, en el art. 20, incluido en el Título II dedicado a la atención integral, de los derechos que poseen estas mujeres. Los derechos enumerados son:

- A la información sobre los distintos recursos de atención. 
- A la atención especializada.

- A la intimidad y privacidad.

- A la atención social.

- A la atención psicológica.

- A la asistencia jurídica.

- A la asistencia sanitaria.

- A la escolarización inmediata de los menores.

II.2. Derechos de las mujeres inmigrantes víctimas de violencia de género

En el 2009 se produjo un importante cambio en la legislación de extranjería al promulgarse la L.O. 2/2009, de in de diciembre, de reforma de la L.O. 4/2000, de II de enero, sobre derechos y libertades de los extranjeros en España y su integración social ${ }^{4}$, la cual quería ser un reflejo de la realidad migratoria imperante en el país.

Como siempre, tuvo sus defensores y sus detractores. Pero todos ellos estaban pendientes de la redacción final para conocer el resultado. Como se dice en la Exposición de Motivos, las causas justificadoras de la reforma son tres:

$\mathrm{I}^{\circ}$. Necesidad de incorporar la jurisprudencia del TC.

$2^{\circ}$. Necesidad de incorporar las directivas europeas sobre inmigración.

$3^{\circ}$. Necesidad de adaptar esta legislación a la nueva realidad migratoria en España.

Las novedades dentro de los derechos que poseen las mujeres extranjeras víctimas de violencia de género son las que nos interesan y paso a enumerarlas a continuación:

- Nueva redacción dada al artículo i9 que habla sobre los «efectos de la reagrupación familiar en circunstancias especiales» estableciéndose que la autorización se concederá «sin necesidad de ningún otro trámite administrativo».

- En el apartado $2^{\circ}$ del párrafo 2 se habla concretamente de la mujer reagrupada víctima de violencia de género, quien puede obtener una autorización independiente a la de su cónyuge desde el mismo momento en que haya obtenido a su favor una orden de protección ${ }^{5}$ o se tenga un informe del Ministerio Fiscal donde se indique la existencia de indicios de violencia de género.

- Se introduce el art. 3I bis que habla sobre la residencia temporal y trabajo de las mujeres extranjeras víctimas de violencia de género.

Es un artículo totalmente nuevo donde se establece que las mujeres extranjeras víctimas de violencia de género, sin importar su situación administrativa, tienen

\footnotetext{
${ }^{4} \mathrm{BOE} \mathrm{n}^{\circ} 299$, de 12 de diciembre de 2009 .

${ }^{5}$ La orden de protección es un instrumento judicial diseñado para proteger a la víctima de la violencia de género frente a todo tipo de agresiones. Por medio de una resolución judicial se reconoce la existencia de una situación objetiva de riesgo para la víctima, ordenando su protección durante la tramitación del procedimiento penal. Con esta orden de protección las mujeres víctimas de violencia de género pueden acreditar su condición de víctima de violencia de género, dando lugar al reconocimiento de los derechos económicos y sociales que se recogen en la LOVG. Para las mujeres inmigrantes la orden de protección les da la oportunidad de obtener una autorización de residencia independiente de la de su cónyuge en el caso de haber sido reagrupadas o una autorización de residencia provisional cuando se encuentren en una situación administrativa irregular.
} 
garantizados los derechos recogidos en la LOVG, incluido el derecho a la asistencia jurídica gratuita del que hablaremos posteriormente.

Se dice que si cuando se denuncie la situación de violencia de género se pusiera de manifiesto la situación de irregularidad administrativa, el procedimiento sancionador quedará suspendido hasta la finalización del procedimiento penal que se haya iniciado por la existencia de una situación de violencia de género. Esta mujer puede solicitar una autorización de residencia y trabajo por circunstancias excepcionales desde el momento en que se dicte la orden de protección o, en su defecto, informe del Ministerio Fiscal exponiendo la existencia de indicios de violencia de género. La autorización no será resuelta hasta la conclusión del proceso penal. A pesar de esto, se puede conceder una autorización provisional, la cual concluirá cuando se conceda o deniegue de modo definitivo la autorización por circunstancias excepcionales.

Una vez concluido el proceso penal con una sentencia condenatoria, se notifica a la interesada la concesión de la autorización temporal.

En caso contrario, si no se deduce la situación de violencia de género, el procedimiento administrativo sancionador continúa.

- En el artículo 40 se regulan los supuestos específicos de exención de la situación nacional de empleo, estableciéndose que no se tendrá en cuenta la misma, entre otros casos, cuando el contrato vaya dirigido a aquellas extranjeras que hayan obtenido una autorización de residencia por circunstancias excepcionales en aquellos supuestos que establezca el Reglamento y «en todo caso, cuando se trate de víctimas de violencia de género o de trata de seres humanos».

Todo esto se reguló en la nueva Ley de Extranjería en el año 2009 esperando un posterior desarrollo reglamentario de muchos de los preceptos. Este desarrollo se ha hecho de rogar, pues se dio un plazo de seis meses para el dictamen del reglamento, el cual ha visto la luz en abril de 20II, casi un año después del cumplimiento del plazo máximo estipulado ${ }^{6}$.

Antes de analizar los artículos del tan esperado Reglamento que desarrollan los derechos recogidos en la LO 2/2009 de reforma de la LO 4/2000 sobre los derechos y libertades de los extranjeros en España y su integración social, debemos hacer una pequeña mención al reconocimiento del derecho de asilo de las mujeres extranjeras víctimas de violencia de género ${ }^{7}$.

Este derecho aparece regulado en la Ley I2/2009, de 30 de octubre, reguladora del derecho de asilo y de la protección subsidiaria ${ }^{8}$.

En el art. 2 de la mencionada ley se recoge lo que se entiende por asilo estableciendo que es «la protección dispensada a los nacionales no comunitarios o a los apátridas a quienes se reconozca la condición de refugiado en los términos definidos en el artículo 3 de esta Ley y en la Convención sobre el Estatuto de los Refugiados hecha en Ginebra el 28 de julio de 1951, y su Protocolo, suscrito en Nueva York el 31 de enero de 1967».

\footnotetext{
${ }^{6}$ Real Decreto 557/20II, de 20 de abril, por el que se aprueba el Reglamento de la LO 4/2000, sobre derechos y libertades de los extranjeros en España y su integración social tras su reforma por Ley Orgánica 2/2009 (BOE $\mathrm{n}^{\circ}$ IO3, de 30 de abril de 20II).

${ }^{8} \mathrm{BOE} \mathrm{n}^{\circ}{ }_{2} 63$, de 3I de octubre de 2009 .
} 
El art. 3, al que alude el artículo anterior, dice que la condición de refugiado será reconocido «a toda persona que, debido a fundados temores de ser perseguida por motivos de raza, religión, nacionalidad, opiniones políticas, pertenencia a determinado grupo social, de género u orientación sexual, se encuentra fuera del país de su nacionalidad y no puede o, a causa de dichos temores, no quiere acogerse a la protección de tal país, o al apátrida que, careciendo de nacionalidad y hallándose fuera del país donde antes tuviera su residencia habitual, por los mismos motivos no puede o, a causa de dichos temores, no quiere regresar a el, $\gamma$ no esté incurso en alguna de las causas de exclusión del artículo 8 o de las causas de denegación o revocación del artículo 9».

En el art. 6, englobado dentro del Título I dedicado a la protección internacional, concretamente, en el Capítulo «de las condiciones para el reconocimiento del derecho de asilo», se nos habla de los actos de persecución: deberán:

«1. Los actos en que se basen los fundados temores a ser objeto de persecución (...)

a) Ser suficientemente graves por su naturaleza o carácter reiterado como para constituir una violación grave de los derechos fundamentales (...),

b) Ser una acumulación lo suficientemente grave de varias medidas, incluidas las violaciones de derechos humanos, como para afectar a una persona de manera similar a la mencionada en la letra a).

2. Los actos de persecución definidos en el apartado primero podrán revestir (...) las siguientes formas:

a) Actos de violencia física o psíquica, incluidos los actos de violencia sexual;

b) Medidas legislativas, administrativas, policiales o judiciales que sean discriminatorias en sí mismas o que se apliquen de manera discriminatoria;

c) Procesamientos o penas que sean desproporcionados o discriminatorios; discriminatorias;

d) Denegación de tutela judicial de la que se deriven penas desproporcionadas o

e) Procesamientos o penas por la negativa a prestar servicio militar en un conflicto en el que el cumplimiento de dicho servicio conllevaría delitos o actos comprendidos en las cláusulas de exclusión establecidas en el apartado segundo del artículo 8 de esta Ley;

f) Actos de naturaleza sexual que afecten a adultos o a niños».

Después del dictamen de la nueva ley de asilo se recoge en el articulado la posibilidad de que sea reconocida la condición de refugiado a aquella persona que tenga fundados temores de ser perseguida debido a motivos de género y orientación sexual. Se incluye en esta opción la posibilidad de que una mujer pueda alegar motivos de género para ser perseguida en su país de origen y así solicitar asilo en un tercer país.

A continuación pasaremos a analizar los artículos del Reglamento donde se desarrollan más extensamente los artículos correspondientes a las mujeres víctimas de violencia de género vistos en la Ley de Extranjería dictada en el año 2009.

En el art. 59.2 b) se habla de la autorización de residencia y trabajo independiente de la persona reagrupante, estableciendo que su tramitación tendrá el carácter de preferente y una duración de 5 años. Este artículo se encuentra incluido dentro del capítulo II, incluido en el Título IV, encargado de la residencia temporal por reagrupación familiar.

En el Título V se regula la residencia temporal por circunstancias excepcionales, encontrándose entre ellas las situaciones de violencia de género. En concreto, el capítulo II se encarga de la residencia temporal por circunstancias excepcionales de las mujeres 
extranjeras víctimas de violencia de género. Este capítulo está compuesto por los artículos I3I-I34:

- El artículo I3I regula:

- El procedimiento sancionador iniciado por infracción del art. 53.I a) queda en suspenso si se inició; si no ha sido así, queda pospuesto.

- Deber de informar a la mujer de las posibilidades que le asisten y de los derechos de acuerdo a la L.O.V.G.

- El artículo I32 establece:

- La posibilidad de solicitar la autorización de residencia y trabajo por circunstancias excepcionales desde el momento del dictamen de la orden de protección (aquí se ve la importancia de denunciar para poder obtener la orden de protección que es buena para la seguridad de la mujer y de las personas a su cargo).

- La posibilidad de solicitar en cualquier momento la autorización de residencia por circunstancias excepcionales a favor de los/las hijos/as menores o la autorización de residencia y trabajo por circunstancias excepcionales a favor de los/las hijos/as mayores de i6 años que se encuentren en España en el momento de la denuncia (Imposibilidad de solicitar esta autorización para aquellos/as hijos/as que se encuentren en el país de origen).

- Carácter preferente.

- El artículo I33 nos habla de la:

- Concesión de la autorización de residencia y trabajo provisional a favor de la mujer y de los hijos menores, debiendo existir una orden de protección o un informe del Ministerio Fiscal.

- Concesión de esta autorización implica:

- La posibilidad de trabajar en cualquier ocupación, sector de actividad y ámbito territorial.

- El mismo alcance para la autorización de sus hijos/as.

- Su vigencia está condicionada a la concesión o denegación de la autorización definitiva.

- En un mes desde la concesión debe solicitar la Tarjeta de Identidad de Extranjero que tendrá una vigencia anual sin que aparezca el carácter de provisional ni la condición de víctima de violencia de género.

- La autoridad judicial que conozca del proceso penal será informada de estas circunstancias.

- El artículo $\mathbf{3} 34$ habla de la conclusión del proceso penal, el cual será puesto en conocimiento de la Oficina de Extranjería y de la Comisaría de Policía:

- Si la sentencia o la resolución judicial es condenatoria:

- En el caso en que se haya solicitado la autorización de residencia y trabajo y ésta se concede. 
- Tendrá una duración de 5 años, sin perjuicio de la posibilidad de acceder a la situación de residencia de larga duración; computándose para ello el tiempo por el que haya sido titular de la autorización provisional.

- En un mes desde la concesión debe solicitar la Tarjeta de Identidad de Extranjero donde constará la posibilidad de residencia y trabajo, pero no la condición de víctima de violencia de género.

- Todo esto es aplicable a la autorización correspondiente a los/las hijos/as.

- Si no solicitó la autorización de residencia y trabajo, debe ser informada de la posibilidad que le asiste de solicitarla para ella y sus hijos/as.

- Tiene un plazo de 6 meses desde la notificación de la sentencia para solicitarla.

- Si se concede la autorización de residencia y trabajo, el procedimiento sancionador resultará archivado.

- Cuando la sentencia o resolución judicial no es condenatoria:

- Si se solicitó la autorización de residencia y trabajo, ésta se denegará y también la de sus hijos/as.

- Pérdida de la eficacia de la autorización provisional.

- Se inicia o se continúa el procedimiento sancionador por infracción del art. 53.I a) de la Ley de Extranjería?

\section{Vulnerabilidad de las mujeres inmigrantes}

Concepto de vulnerabilidad: el diccionario de la RAE nos remite a la cualidad de vulnerable. Vulnerable es descrito como un adjetivo que significa «que puede ser herido o recibir lesión, física o moral».

La vulnerabilidad es la antesala de la exclusión. La vulnerabilidad social tiene dos componentes que la explican ${ }^{\text {Io }}$ :

I. La inseguridad e indefensión que experimentan las comunidades, los grupos, las familias y los individuos en sus condiciones de vida como consecuencia del impacto que provoca algún tipo de evento natural, económico y social de carácter traumático.

2. El manejo de recursos y estrategias que usan para afrontar esos efectos.

De acuerdo con la Federación Internacional de la Cruz Roja y la Media Luna Roja (2000), «las personas vulnerables son aquellas que corren peligro en situaciones en las que están amenazadas tanto su vida como su capacidad para vivir con un mínimo de seguridad social $y$ económica $y$ de dignidad humana».

${ }^{9}$ Artículo 53.I a) de la Ley Orgánica 2/2009: «Encontrarse irregularmente en territorio español, por no haber obtenido la prórroga de estancia, carecer de autorización de residencia o tener caducada más de tres meses la mencionada autorización, y siempre que el interesado no hubiere solicitado la renovación de la misma en el plazo previsto reglamentariamente».

Io «Documentos presentados en la VII Asamblea General de Cruz Roja Española» los días 25, 26 y 27 de marzo de $201 \mathrm{I}$, p. 26. 
¿Por qué las mujeres inmigrantes son vulnerables?

La vulnerabilidad de las mujeres inmigrantes se hace patente en los componentes enumerados a continuación ${ }^{\text {II }}$

I. Vulnerabilidad física y material: Muchas mujeres que se encuentran en España no han participado ni participan en la esfera productiva remunerada y el acceso a la educación no ha sido en un plano de igualdad con los varones. No se les ha permitido controlar su ciclo reproductivo, poseyendo una menor cantidad de recursos materiales.

2. Vulnerabilidad social y organizativa: «las mujeres extranjeras son excluidas del proceso de toma de decisiones en el ámbito económico, social y político junto a la gran mayoría de españolas en concepto de mujeres (discriminación por género) $y$ en concepto de inmigrantes (discriminación por etnia). Este colectivo no suele gozar de amplias redes sociales, sobre todo al principio el proceso migratorio».

3. Vulnerabilidad actitudinal: «para muchas de estas mujeres el hecho migratorio se convierte, quizás no en una etapa de crisis, pero sí en una época de transición en ámbitos personales y laborales. (...) Es importante el desarrollo de programas que contribuyan a disminuir la vulnerabilidad fortaleciendo las capacidades de las personas».

Las mujeres inmigrantes viven una doble o triple situación de vulnerabilidad pues pertenecen a dos o tres categorías de exclusión ${ }^{\mathrm{I} 2}$ :

a) Ser mujer.

b) Ser inmigrante.

c) En muchos casos: indocumentada.

Aquellas que dejaron su país con la idea de encontrar un futuro mejor en el país de destino son más vulnerables debido:

- Duelo migratorio: consiste en la situación psicológica especial que condiciona las percepciones y el comportamiento de gran parte de las mujeres que toman la decisión de migrar. La mujer se encuentra desarraigada, pues ha dejado su país para buscar algo mejor, pero se encuentra sola en un país extraño, quizás sin conocer el idioma, un país donde la cultura, el modo de vida, la comida es diferente al de su país de procedencia. Ha dejado atrás a su familia.

- Choque cultural: las sociedades, culturas y nacionalidades de las que provienen y a donde llegan son diferentes.

- Carencia de redes sociales naturales en las que apoyarse: el viaje supone romper con los vínculos familiares y de amistad, junto a esto, en muchos casos, existen también dificultades económicas, lingüísticas y/o administrativas. Sus interminables horas de trabajo más la exigencia de realizar las tareas del hogar y el cuidado de los/las hijos/as, si se encuentran residiendo con ella, y la existencia de una cierta tendencia a vivir en los guetos creados no ayudan a que se produzca una participación y un contacto con la sociedad autóctona y un acceso a la información sobre los derechos y/u obligaciones que se tienen.

\footnotetext{
${ }^{\text {II }}$ Di Pane Sánchez, J.C. «Inmigración y violencia intercultural desde una perspectiva de género». Título de Experto Universitario en Educación y Prevención en Materia de Violencia de Género. Dentro del módulo s: Sociedad y Violencia.

${ }^{\text {I2 }}$ Cfr. Ibídem.
} 
- Fuerte dependencia respecto de la pareja. fuente de protección.

- Percepción de las instituciones públicas como una amenaza más que como una

- Miedo a no ser creída o a que la denuncia de violencia de género pueda afectar a su proceso de regularización.

Ana María Uría Pelayo ${ }^{\mathrm{I} 3}$ habló en una ponencia sobre la vulnerabilidad de estas mujeres y de las circunstancias que aumentan la vulnerabilidad ante la violencia de género y que dificultan la ruptura del ciclo violento que se produce. Esta abogada se está refiriendo al llamado «Síndrome de Ulises», el cual se manifiesta de la siguiente manera:

a. Sentimiento de soledad.

b. Sentimiento de fracaso.

c. Lucha por la supervivencia.

d. Miedo y terror por las situaciones tan difíciles por las que atraviesan.

El síndrome se produce debido a dos factores que son:

I. El duelo migratorio:

a. Por la familia y amigos.

b. Por la lengua.

c. Por la cultura.

d. Por la tierra.

e. Por el status social.

f. Por perder el contacto con el grupo étnico de origen.

g. Por la pérdida de salud asociado al proceso migratorio. Proceso de adaptación a la nueva vida.

2. Situaciones de estrés.

Según esta autora, son siete los instrumentos que utilizan los maltratadores contra las mujeres inmigrantes:

I $^{\circ}$. Aislamiento: por ejemplo, no deja que aprenda el idioma del país de residencia.

$2^{\circ}$. Amenazas.

$3^{\circ}$. Intimidación.

$4^{\circ}$. Manipulación sobre su ciudadanía o residencia.

$5^{\circ}$. Abuso económico: consiste en la privación de recursos para el bienestar físico y psicológico.

$6^{\circ}$. Abuso emocional.

${ }^{13}$ Uría Pelayo, A.M.: «La violencia de género sobre las mujeres inmigrantes y otros colectivos de mujeres más vulnerables». Ana María Uría Pelayo es abogada del Ilustre Colegio de Abogados de Cantabria y miembro de su Comisión de Extranjería y vocal de la Subcomisión de Extranjería del CGAE (consultado en: http://www.abogados.es/portalABOGADOS/archivos/ficheros/I208768990037.PDF; última consulta en noviembre de 20II) 
$7^{\circ}$. Uso de los /las hijos/as.

\section{El derecho a la asistencia jurídica gratuita para la mujer inmigrante}

IV.r. Definición de este derecho según la L.O. I/ı996, de ıo de enero, de Asistencia Jurídica Gratuita ${ }^{\mathrm{I}}$

El derecho a la asistencia jurídica gratuita se regula en el art. II9 CE: «La justicia será gratuita cuando así lo disponga la ley $\gamma$, en todo caso, respecto de quienes acrediten insuficiencia de recursos para litigar».

Este derecho se encuentra íntimamente relacionado con el derecho recogido en el art. 24.I CE que se encarga de regular la tutela judicial efectiva: «Todas las personas tienen derecho a obtener la tutela de los jueces $y$ tribunales en el ejercicio de sus derechos e intereses legítimos, sin que, en ningún caso, pueda producirse indefensión».

El art. I de la Ley I/1996, de io de enero, nos indica el objeto de la misma estableciendo que es «determinar el contenido de la asistencia jurídica gratuita al que se refiere el artículo 119 de la Constitución y regula el procedimiento para su reconocimiento y efectividad» (Perdices Mañas 2006, 5I y ss.), recogiendo, además, unos mecanismos para facilitar el acceso a la Justicia en pie de igualdad a las partes procesales (arts. I4 y 24 Constitución Española).

Según expone en su ponencia Antonio J. Perdices Mañas «además de la normativa de la asistencia jurídica 'gratuita' existen en nuestro ordenamiento jurídico principios y normas para garantizar el acceso a la justicia en pie de igualdad, desde el momento en que tenemos contacto con la Administración de Justicia» (Perdices Mañas 2006).

«El concepto de 'ayuda legal' para el acceso a la Justicia se articula en la Constitución como un derecho fundamental», recogido en los arts. $24, \mathrm{I} 4,9 \mathrm{y} \mathrm{IO} .2^{\circ}$, los cuales se pueden invocar en amparo ante el Tribunal Constitucional, «en tanto que la 'Justicia Gratuita' no es más que una manifestación de aquel, que afecta al aspecto económico, y que se halla relegado a un principio inspirador en el art. 119» el cual se encuentra carente del amparo de los arts. I6I.I. b y $53.2 \mathrm{CE}$.

El art. II9 CE fue desarrollado posteriormente por la Ley Orgánica I/1996, de Io de enero, de asistencia jurídica gratuita. En el art. 2de esta ley se establece quiénes tendrán derecho a esta asistencia, siempre que acrediten que tienen insuficiencia de recursos para litigar ${ }^{15}$. Este precepto ha sido modificado tras la sentencia del Tribunal Constitucional 95/2003 de 22 de mayo; pues previamente a esta sentencia, se otorgaba este derecho a los extranjeros que residieran legalmente en España. La mencionada sentencia declaró inconstitucional la expresión «legalmente», pero no así la expresión «residieran». Por ello, el derecho a la asistencia jurídica gratuita se extendió, tras la sentencia del Tribunal Constitucional, a todos los extranjeros que residan en España tanto de modo legal como ilegal.

Este derecho comprende las siguientes prestaciones:

- Asesoramiento y orientación gratuitos con carácter previo al inicio del proceso.

- Asistencia de abogado/a al detenido o preso.

\footnotetext{
${ }^{14} \mathrm{BOE} \mathrm{n}^{\circ} \mathrm{II}$, de I2 de enero de I996.

${ }^{15}$ En el apartado I del citado artículo se establece que tendrán derecho a la asistencia jurídica gratuita «los ciudadanos españoles, los nacionales de los demás Estados miembros de la Unión Europea y los extranjeros que se encuentren en España, cuando acrediten insuficiencia de recursos para litigan».
} 
- Defensa y representación gratuitas por abogado/a y procurador/a en el procedimiento judicial.

- Inserción gratuita de anuncios o edictos, en el curso del proceso que se deben publicar preceptivamente en periódicos oficiales.

- Exención del pago de depósitos para la interposición de recursos.

- Asistencia pericial gratuita en el proceso.

- Obtención gratuita de copias, testimonios, instrumentos y actas notariales.

- Reducción del 80\% de los derechos arancelarios que correspondan por determinadas actuaciones notariales.

- Reducción del 80\% de los derechos arancelarios que correspondan por determinadas actuaciones de los registros de la propiedad y mercantil.

IV.2. Requisitos para su otorgamiento.

¿En qué consiste la solicitud de la asistencia jurídica? Se trata de «una declaración de voluntad, efectuada por el titular de un derecho o interés legítimo, de querer actuar en defensa del mismo (administrativa o judicialmente), en el plazo determinado legalmente, con el concurso de una asistencia técnica (abogado/a y procurador/a), incluso en los que quepa autodefensa, $y$ con cuantos más beneficios le puedan corresponder conforme a la Ley 1/96 y normativa complementaria, sin que ello le suponga un quebranto económico que le lleve a desatender las necesidades de sustento propio y las de su familia (especialmente en los supuestos en que se acredite la carencia de recursos para litigar)» (Perdices Mañas 2006).

Como dice Antonio J. Perdices Mañas, «el momento para instar la ayuda o asistencia legal en defensa de los derechos e intereses legítimos coincide con el mismo momento en que surgen la necesidad y la voluntad de querer actuar en su defensa» (Perdices Mañas 2006).

Los requisitos básicos necesarios que deben cumplirse para solicitar esta asistencia jurídica son regulados en el art. 3 de la ley que estamos estudiando:

- Los recursos e ingresos económicos, computados anualmente por todos los conceptos y por unidad familiar, no pueden superar el doble del IPREM.

- Si supera el doble del IPREM, pero no el cuádruple, la Comisión de Asistencia Jurídica Gratuita atenderá a las circunstancias de la familia de la solicitante, el número de hijos/as o familiares a su cargo, el estado de salud, minusvalía, obligaciones económicas, etc.

- La persona solicitante litiga en defensa de derechos e intereses propios.

La LO I/2004, de 28 de diciembre, de Medidas de Protección Integral contra la Violencia de Género se encarga de modificar el apartado 5 del artículo 3 de la Ley I/ı996, de Io de enero, de Asistencia Jurídica Gratuita disponiendo que se excluye «la necesidad de acreditar previamente la carencia de recursos económicos por parte de las víctimas de violencia de género y establece la inmediatez en la prestación de la asistencia jurídica gratuita» (Mayán Santos M.E, 2006). 


\section{IV.3. Intervención preceptiva de abogado/a y procurador/a}

Siempre que vemos en los juicios a las partes, éstas cuentan con asistencia letrada y representación por medio de procurador/a, pero no siempre es necesaria su presencia en los procesos civiles o penales.

El art. 23.I LEC recoge el principio general por el cual las partes comparecerán en el proceso civil preceptivamente por medio de procurador/a legalmente habilitado/a para actuar en el tribunal que conozca del juicio. En el párrafo 2 del mismo artículo se enumeran los supuestos en los cuales las partes pueden no servirse de procurador/a, añadiendo algunos supuestos que se contienen en las leyes especiales:

$\mathrm{I}^{\circ}$. Juicios verbales cuya cuantía no exceda de 900 .

$2^{\circ}$. Petición inicial en los procesos monitorios.

$3^{\circ}$. En los juicios universales, cuando se limite la comparecencia a la presentación de títulos de crédito o derechos, o para concurrir a Juntas.

$4^{\circ}$. En aquellos incidentes relativos a impugnación de resoluciones en materia de asistencia jurídica gratuita y cuando se soliciten medidas urgentes con anterioridad al juicio.

La asistencia de letrado/a también aparece regulada en la Ley de Enjuiciamiento Civil, en concreto en el art. 3I:

«1. Los litigantes serán dirigidos por abogados habilitados para ejercer su profesión en el tribunal que conozca del asunto. No podrá proveerse a ninguna solicitud que no lleve la firma de abogado.

2. Exceptuándose solamente:

$1^{\circ}$. Los juicios verbales cuya cuantía no exceda de goo y la petición inicial de los procedimientos monitorios, conforme a lo previsto en esta Ley.

$2^{\circ}$. Los escritos que tengan por objeto personarse en juicio, solicitar medidas urgentes con anterioridad al juicio o pedir la suspensión urgente de vistas o actuaciones. Cuando la suspensión de vistas o actuaciones que se pretenda se funde en causas que se refieran especialmente al abogado también deberá éste firmar el escrito, si fuera posible».

Normalmente, la mujer víctima de violencia de género inicia el proceso de denuncia de su situación interponiendo una denuncia contra el agresor, por tanto, inicia un proceso penal contra él.

En el proceso penal, no es preceptivo que acuda representada de abogado/a en el inicio del proceso, únicamente en los juicios de faltas.

Por tanto, la mujer víctima de violencia de género está en todo su derecho de solicitar la asistencia letrada para que la acompañe en todo el proceso judicial penal.

IV.4. Solicitud del derecho a la asistencia jurídica gratuita por mujeres inmigrantes en situación administrativa irregular

Cuando nos encontremos ante un proceso judicial o procedimiento administrativo cuya causa directa o indirecta se encuentra en una situación de violencia de género, se procederá de modo inmediato a la designación de un/a abogado/a de oficio dentro del turno especializado en la defensa de las víctimas de violencia de género que a tal efecto tenga el Colegio de Abogados/as correspondiente. Este/esta abogado/a debe informar a la mujer del derecho que le asiste a obtener una asistencia jurídica gratuita; pero debe advertirle que en 
el supuesto de que no le sea reconocido este derecho deberá abonar los honorarios correspondientes.

En estos casos no es necesario acreditar previamente la insuficiencia de medios económicos, pero tras presentar la solicitud, en el plazo de 5 días se debe aportar la documentación necesaria, pues en caso contrario la solicitud será archivada.

Centrándonos en las mujeres inmigrantes que son víctimas de violencia de género, ya hemos expuesto que son un colectivo más vulnerable debido a los distintos motivos que hemos enumerado en apartados anteriores ${ }^{16}$.

La LOVG habla del derecho a la asistencia jurídica gratuita en el art. 20: «las mujeres víctimas de violencia de género que acrediten insuficiencia de recursos para litigar, en los términos establecidos en la Ley Orgánica 1/1996, de 10 de enero, de Asistencia Jurídica Gratuita, tienen derecho a la asistencia y representacióngratuitas por Abogado y Procurador en todos los procesos y procedimientos administrativos que tengan causa directa o indirecta en la violencia padecida.(...) En todo caso, se garantizará la defensa jurídica, gratuita y especializada de forma inmediata a todas las víctimas de violencia de género que la soliciten, sin perjuicio de que si no se les reconoce con posterioridad el derecho a la asistencia jurídica gratuita, éstas deberán abonar al abogado los honorarios devengados por su intervención».

La mujer inmigrante que tiene sus papeles en regla, es decir, que posee una autorización de residencia o de residencia y trabajo, se encuentra con las mismas dificultades con las que se puede encontrar una mujer española que solicita la asistencia jurídica gratuita: dificultad para presentar los papeles solicitados, miedo ante la incertidumbre de lo que sucederá hasta el momento del inicio del proceso, durante el mismo y cuando éste acabe, incertidumbre por el futuro a corto, medio y largo plazo, miedo por sus hijos/as si los tiene,... y no se puede olvidar que siempre la justicia transmite «terror» por lo desconocido y porque todo el proceso impone para quien no está acostumbrado a la jerga jurídica y a todo el proceso que se le presenta.

El mayor problema se presenta cuando se trata de una mujer inmigrante que no posee ningún tipo de autorización para permanecer en España de modo legal la que se decide a acudir a los Juzgados a interponer una denuncia por malos tratos y solicitar un/a abogado/a de oficio. El problema surge porque desde que la mujer entrega la solicitud, los trámites se inician, pero se sabe de antemano que este derecho no será concedido ante la falta de documentación que acredite la insuficiencia de recursos para litigar. En mi más humilde opinión, más que por la falta de documentación acreditativa de la escasez o insuficiencia de recursos económicos para litigar, la solicitud es rechazada de antemano porque la mujer no presenta la autorización de residencia y trabajo o de residencia únicamente, y al no presentar esta autorización, el resto de documentación exigida no se puede presentar.

Con este rechazo, sin entrar a valorar el resto de documentación que se puede presentar, se está produciendo una situación de discriminación y de vulneración del derecho que tiene toda persona, porque estas mujeres también son personas aunque haya gente que no considere esta afirmación como cierta, a ser representada y asesorada por un/a abogado/a y procurador/a.

Si no se concede este derecho a la asistencia jurídica gratuita se está privando a la persona de la posibilidad de acceder a dos derechos recogidos en nuestro texto constitucional: la justicia gratuita del art. II9 CE y la tutela judicial efectiva del art. 24.I CE.

\footnotetext{
${ }^{16}$ Sobre la vulnerabilidad de la mujer inmigrante víctima de violencia de género hemos hablado en el apartado III del artículo.
} 
En un primer momento, antes de la reforma realizada tras el dictamen de la sentencia del Tribunal Constitucional 95/2003, los extranjeros sin residencia legal tenían acceso a la asistencia jurídica gratuita para los procedimientos penales y el contenciosoadministrativo sobre el derecho de asilo. Tras esta sentencia que declara inconstitucional el término «legalmente», pero no el término «que residan», todo extranjero residente en España tiene derecho a esta asistencia jurídica gratuita para poder defenderse en cualquier ámbito jurídico. En consecuencia, la mujer inmigrante «sin papeles» que acredite su residencia en España tiene derecho a la concesión de esta asistencia jurídica gratuita con los requisitos exigidos por la ley.

Muchas de estas mujeres vienen reagrupadas por sus parejas, quienes, como consecuencia de sus pensamientos machistas y retrógrados, se hacen cargo de la custodia de toda su documentación sin permitirle el acceso a ella. Por tanto, quien se hace cargo de la renovación de la documentación, no es la mujer, sino su pareja. Aquí se ve claramente la situación de vulnerabilidad: fuerte dependencia, no sólo emocional, de la mujer hacia su pareja y el miedo ante el cumplimiento de las amenazas de dejarla sin su situación legal.

En muchas ocasiones, cuando la mujer se decide a interponer la denuncia por violencia de género su situación administrativa no es legal como sucedía cuando llegó a nuestro país, sino que ya se encuentra en situación administrativa irregular porque su pareja no se ha encargado de renovar la autorización de residencia.

La mujer podrá presentar el pasaporte con el sello de entrada en nuestro país, podrá presentar su alta en el padrón municipal mediante la solicitud del empadronamiento (si se produjo), podrá presentar toda clase de documentación que se encargue de acreditar que no dispone de medios económicos suficientes (ni insuficientes) para poder pagar a un/a abogado/a y procurador/a que le represente en el largo proceso judicial, pues carece de una autorización que le permita encontrar trabajo. Podrá presentar un informe redactado por la asociación, ONG que le asista, que le dé cobijo mientras toda la situación se «normaliza» (si es que puede normalizarse en algún momento), pero seguro que esta clase de documentos la Comisión de la Asistencia Jurídica Gratuita no la tendría en cuenta a la hora de valorar los recursos económicos de que dispone la mujer extranjera.

Entonces, ¿qué les queda a estas mujeres? ¿Regresar a su país con el orgullo y su cuerpo más magullado todavía por un país en el que pusieron toda su esperanza de conseguir un futuro mejor?

El artículo 20 LOVG habla del derecho a la asistencia jurídica gratuita que asiste a las mujeres víctimas de violencia de género. El artículo 22 de la $\mathrm{LO} 2 / 2009$, recoge este derecho para los extranjeros, estableciendo que lo tendrán aquellos extranjeros que se hallen en España para cualquier jurisdicción en las mismas condiciones que los españoles cuando carezcan de recursos económicos.

- Derecho a asistencia letrada.

- Asistencia de intérprete.

Pues bien, este derecho no se lleva a cabo o no se ejercita en el caso de las mujeres extranjeras víctimas de violencia de género que se encuentran en situación administrativa irregular, pues cuando, después de toda la situación vivida y una vez decididas a interponer la denuncia por violencia de género contra su pareja o esposo, se encuentran con que no les es concedido el derecho a la asistencia jurídica gratuita por falta de documentación. 
¿Cuál es la documentación exigida, por ejemplo, en Salamanca para solicitar la asistencia jurídica gratuita? ${ }^{\text {I7 }}$

I. Fotocopia del NIF, TIE en vigor, pasaporte en vigor.

2. Declaración impositiva de la unidad familiar.

3. Certificado de la administración tributaria de no haber presentado declaración si no otorga el consentimiento para que la comisión y el colegio de abogados obtengan directamente de la Administración Tributaria la acreditación.

4. Certificado catastral.

5. Si se alegan cargas sobre el inmueble, nota simple del registro de la propiedad.

6. Certificado de los centros de trabajo y de las altas y bajas de la Seguridad Social.

7. Certificado de la empresa acreditativo de los ingresos brutos mensuales.

8. Certificado del servicio público de empleo estatal donde conste la percepción de ayuda por desempleo y el período.

9. Certificado de cobro de pensiones públicas.

Para mí es obvia la respuesta que hay que dar a la pregunta siguiente: ¿qué documentos va a poder presentar una mujer inmigrante en situación irregular víctima de violencia de género que, posiblemente, haya abandonado su hogar con lo puesto? Ninguno, porque para nuestra Administración ella no se encuentra aquí. Bueno, quizás pueda presentar el pasaporte donde se pueda comprobar el sello de entrada en nuestro país. Pero el resto de documentos, ¿de dónde los obtiene?

Es muy probable que los trabajos en los que haya estado pertenezcan a la denominada «economía sumergida» y, por lo tanto, no haya tenido un contrato de trabajo nunca. Es decir, no puede presentar un certificado de la empresa donde aparezcan los ingresos brutos; tampoco puede aportar el certificado de los centros de trabajo ni de las altas y bajas en la Seguridad Social pues nunca se ha producido este hecho. En consecuencia, tampoco puede presentar un certificado del servicio público de empleo estatal, pues nunca habrá tenido derecho a cobrar una prestación por desempleo y tampoco habrá cobrado nunca una pensión pública.

Entonces, ¿qué ocurre? Ya no puede presentar esta documentación, que sólo la pueden aportar aquellas mujeres extranjeras que tengan sus «papeles en regla». ¿No tiene derecho a que se le conceda la asistencia jurídica gratuita para poder proteger su interés jurídico vulnerado? ¿Qué más pruebas que éstas para acreditar la carencia de recursos económicos para pagar a un abogado/a y procurador/a propio elegido/a por ella misma?

Posiblemente lo único que obre en su poder sea el pasaporte y se puede solicitar un certificado de empadronamiento que acredite desde cuándo se encuentra en España o, al menos, en esa localidad, siempre y cuando, en algún momento supo que podía acceder a este trámite aunque no tuviese la autorización de residencia o la autorización de residencia y trabajo.

Me consta que a estas mujeres les es rechazada la solicitud de asistencia jurídica gratuita por falta de documentación, cuando esa documentación no se presenta porque se

\footnotetext{
${ }^{17} \mathrm{http} / /$ www.icasal.com/ciudadano/ventanilla_unica?seccion=solicitud_de_justicia_gratuita
} 
carece de ella o, mejor dicho, porque aunque se solicitase los resultados serían negativos, pues para la Seguridad Social, por ejemplo, esa mujer no existiría.

Nos encontramos ante una vulneración flagrante del derecho a la tutela judicial efectivo al que debe tener acceso toda persona. Con esta vulneración se está privando a la mujer de acceder a la justicia y poder denunciar el delito del que ha sido víctima, pues no posee recursos económicos con los que poder pagar a un/a letrado/a y procurador/a que necesita para iniciar el proceso penal.

Ante esta situación, ¿qué les queda a estas mujeres?

\section{Bibliografía, legislación y otros recursos}

ALHAMBRA PÉREZ, P. (2005): Guía práctica de la Ley Orgánica 1/2004, de 28 de diciembre, de Medidas de Protección Integral contra la Violencia de Género. Consejo General del Poder Judicial.

DI PANE SÁNCHEZ, J.C.: Inmigración y violencia intercultural desde una perspectiva de género. Perteneciente al Título de Experto Universitario en Educación y Prevención en Materia de Violencia de Género, dentro del módulo I: Sociedad y Violencia.

MAYÁN SANTOS, M.E. (2006): «El reconocimiento del derecho a la asistencia jurídica gratuita», Revista Internauta de Práctica Jurídica I8.

PERDICES MAÑAS, A.J. (2006): Gestión y tramitación de la asistencia jurídica: los servicios de orientación jurídica Y las comisiones de asistencia jurídica. Introducción: ayuda legal o asistencia jurídica. III Jornadas de Asistencia Jurídica Gratuita. Ponencia III. Real e Ilustre Colegio de Abogados de Zaragoza. Celebrado entre los días 23 a 25 de febrero de 2006.

URÍA PELAYO, A.M.: La violencia de género sobre las mujeres inmigrantes $y$ otros colectivos de mujeres más vulnerables (Consultado en: <http://www.abogados.es/portalABOGADOS/archivos/ficheros/1208768990 037.PDF>; última consulta noviembre de 20II).

Ley Orgánica I/ı996, de io de enero, de Asistencia Jurídica Gratuita. Boletín Oficial del Estado nº II, viernes I2 de enero de 1996.

Ley Orgánica I/2004, de 28 diciembre, de Medidas de Protección Integral contra la Violencia de Género. Boletín Oficial del Estado ${ }^{\circ}{ }^{3}$ I3, sábado 29 de diciembre de 2004.

Ley Orgánica 2/2009, de II de diciembre, de reforma de la Ley Orgánica 4/2000, de II de enero, sobre derechos y libertades de los extranjeros en España y su integración social. Boletín Oficial del Estado n 299 , sábado I2 de diciembre de 2009 .

Ley I2/2009, de 30 de octubre, reguladora del derecho de asilo y de la protección subsidiaria. Boletín Oficial del Estado $\mathrm{n}^{\circ} 263$, sábado 3I de octubre de 2009 .

Ley i3/2010, de 9 de diciembre, contra la Violencia de Género de Castilla y León. Boletín Oficial de Castilla y León $\mathrm{n}^{\circ} 243$, lunes 20 de diciembre de 20 io.

Real Decreto 557/20II, de 20 de abril, por el que se aprueba el Reglamento de la Ley Orgánica 4/2000, de II de diciembre, sobre los derechos y libertades de los extranjeros en España y su integración social. Boletín Oficial del Estado n ${ }^{\circ}$ IO3, de 30 de noviembre de 201 I.

VII Asamblea General de Cruz Roja Española (20II): Documentos presentados en la VII Asamblea General de Cruz Roja Española.

www.icasal.com 